\title{
If you haven't published your work, it's time to start
}

\section{David P Stevens}

\section{Collaborative approaches to writing provide a context for undertaking this difficult work, and publication guidelines provide standards for rigorous and useful reports}

$\mathrm{R}$

esearch on healthcare improvement is incomplete until it has been published. Improvement science is now a central component of healthcare. Patients should be able to expect continuous improvement of the care they receive. Systems of care increasingly focus on efficient and effective delivery of care. To these ends, it can be argued that those who engage in improvement have a professional obligation to report their methods and results.

Improving healthcare requires precious resources-time and money. Health systems can not afford the duplication and waste that occurs when others must replicate knowledge independently. Many colleagues regularly publish their improvement innovations in this and other journals. But it is appropriate to explore the challenges as well as the opportunities for a wider commitment to publication by improvement experts. ${ }^{1}{ }^{2}$

First, improvement professionals often consider their work too local or idiosyncratic to merit generalisation to wider settings, even questioning whether a local project could be replicated in other settings. Second, busy clinicians and managers find they simply cannot create time to write. One perception is they have more compelling tasks at hand-providing care and improving their own patient care setting. They often see writing effectively as the work of others. Third, although scholarly publication is the task of academics, it is ironic that publication of innovative improvement is occasionally undervalued in academic settings. Some in academe have considered improvement research less reliable and scholarly than, for example, randomised controlled trials. Fourth, some healthcare institutions have made approval of improvement projects by ethics committees sufficiently daunting that the absence of human subjects or ethics committee approval has sometimes stood in the way of submission for publication. ${ }^{3}$ Lastly, editors of many scholarly journals are unreceptive to results of successful improvement initiatives. Similarly, reviewers frequently pronounce a paper insufficiently rigorous, too qualitative or simply unscientific. In this regard, however, guidelines are available and continually evolving. They offer frameworks on which improvement scholars and editors can agree that ensure that the published work is sound. ${ }^{1}{ }^{4}$

Publication is not the exclusive domain of academics. When a new effective treatment is discovered, it is considered unprofessional, if not unethical, not to report that evidence for better treatment of patients. In the same regard, if a particular practice can make care more effective, efficient, equitable, safer, timely or more patient centred, it is a professional obligation that it is reported and widely implemented. What are effective strategies to assure that publication becomes part of the work of improvement? What might be learned from those who have consistently and successfully published their work?

First, one approach has been to develop a "writing collaborative" together with colleagues. To support writing and hasten publication of effective improvement work, we have tested such a strategy at the conclusion of a recent initiative designed to improve chronic illness care in academic settings, ${ }^{6}$ and have found that groups of improvement experts who meet regularly to share their writing readily progress to successful development of publishable papers. Early on, guidance was provided across the initiative for the submission of applications to institutional review boards at the various sites. When improvement results were aggregated, participants met to share their writing at monthly meetings, either by teleconference or in person. Each participant was expected to present work at these sessions regardless of its stage of development. The first task was simply to develop a descriptive working title. Next, drafting an abstract, even if it was incomplete, was often helpful. As drafts advanced through various stages of development to more polished manuscripts, they were repeatedly presented for review and comment by members of the writing group; using publications guidelines was also helpful. The success of the writing collaborative depended heavily on those who provided careful and extensive criticism in a supportive context.

Second, the review of journal articles for publication is predicated on a classical improvement strategy. New authors can expect that journal reviewers will be exhaustively critical. Reviewers' comments are intended to improve the science, writing and presentation of the work. An author must be prepared for extensive criticism and realise that this is intended to present their work in the best possible form. When responding to reviews, authors should feel free to communicate with editors and reviewers. Editors expect to be engaged by authors. To the new author the review and editorial process often seems to be dogmatic and hierarchical. In fact, publication is at its heart the work of a scholarly community.

Third, improvement experts might consider becoming a journal reviewer. By offering an editor one's area of expertise an improvement scholar becomes part of the writing and scholarly community.

Fourth, as noted above, several publication guidelines have been promulgated for reporting improvement studies and discoveries. ${ }^{145}$ Their wider adoption will support predictable rigour and utility in improvement reports. They remind the author that if the outcomes of improvement work are not well supported by evidence they must be questioned and improved. Authors miss an opportunity when they do not make use of guidelines, which provide a shared set of standards that are increasingly the result of consensus between editors and improvement scholars.

Finally, one should consider writing every day. Some have advised sitting down and writing as little as 15 minutes a day. If one waits until hours can be set aside for the task, one rarely starts. It is time to start.

Qual Saf Health Care 2007; 16:242-243. doi: 10.1136/qshc.2007.024190

Correspondence to: Dr David P Stevens, Quality Literature Program, Dartmouth Center for Evaluative Clinical Sciences, 30 Lafayette Street, Lebanon, New Hampshire 03766, USA;

David.P.Stevens@Dartmouth.edu

\section{REFERENCES}

1 Davidoff F, Batalden P. Toward stronger evidence on quality improvement. Draft publication guidelines: the beginning of a consensus 
project, Qual Saf Health Care 2005; 14: 319-25.

2 Stevens DP. Why new guidelines for reporting improvement research? And why now? Qual Saf Health Care 2005; 14:314.
3 Lynn J, Baily MA, Bottrell M, et al. The ethics of using quality improvement methods in health care. Ann Intern Med 2007; 146:666-73.

4 Speroff T, James BC, Nelson EC, et al. Guidelines for appraisal and publication of PDSA quality improvement. Qual Manag Health Care 2004;13:33-9

5 Moss F, Thomson R. A new structure for quality improvement reports. Qual Health Care 1999;8:76.

6 Stevens DP, Wagner E. Transform resident training in chronic illness care-now. Acad Med 2006:81:685-7.

\section{BMJ Clinical Evidence-Call for contributors}

BMJ Clinical Evidence is a continuously updated evidence-based journal available worldwide on the internet which publishes commissioned systematic reviews. BMJ Clinical Evidence needs to recruit new contributors. Contributors are healthcare professionals or epidemiologists with experience in evidence-based medicine, with the ability to write in a concise and structured way and relevant clinical expertise.

Areas for which we are currently seeking contributors:

- Secondary prevention of ischaemic cardiac events

- Acute myocardial infarction

- MRSA (treatment)

- Bacterial conjunctivitis

However, we are always looking for contributors, so do not let this list discourage you.

Being a contributor involves:

- Selecting from a validated, screened search (performed by in-house Information Specialists) valid studies for inclusion.

- Documenting your decisions about which studies to include on an inclusion and exclusion form, which we will publish.

- Writing the text to a highly structured template (about 1500-3000 words), using evidence from the final studies chosen, within 8-10 weeks of receiving the literature search.

- Working with BMJ Clinical Evidence editors to ensure that the final text meets quality and style standards.

- Updating the text every 12 months using any new, sound evidence that becomes available. The BMJ Clinical Evidence in-house team will conduct the searches for contributors; your task is to filter out high quality studies and incorporate them into the existing text.

- To expand the review to include a new question about once every 12 months.

In return, contributors will see their work published in a highly-rewarded peer-reviewed international medical journal. They also receive a small honorarium for their efforts.

If you would like to become a contributor for BMJ Clinical Evidence or require more information about what this involves please send your contact details and a copy of your CV, clearly stating the clinical area you are interested in, to CECommissioning@bmigroup.com.

\section{Call for peer reviewers}

BMJ Clinical Evidence also needs to recruit new peer reviewers specifically with an interest in the clinical areas stated above, and also others related to general practice. Peer reviewers are healthcare professionals or epidemiologists with experience in evidence-based medicine. As a peer reviewer you would be asked for your views on the clinical relevance, validity and accessibility of specific reviews within the journal, and their usefulness to the intended audience (international generalists and healthcare professionals, possibly with limited statistical knowledge). Reviews are usually 1500-3000 words in length and we would ask you to review between 2-5 systematic reviews per year. The peer review process takes place throughout the year, and our turnaround time for each review is 10-14 days. In return peer reviewers receive free access to BMJ Clinical Evidence for 3 months for each review.

If you are interested in becoming a peer reviewer for BMJ Clinical Evidence, please complete the peer review questionnaire at www.clinicalevidence.com/ceweb/contribute/peerreviewer.jsp 